\title{
Esthetic Smile Perception Among Dental Students at Different Educational Levels
}

\author{
Nebras Althagafi (iD \\ Department of Pediatric Dentistry and \\ Orthodontics, College of Dentistry, \\ Taibah University, AIMadinah \\ AlMunawwarah, 42353, Saudi Arabia
}

Correspondence: Nebras Althagafi Tel +966-564060607

Email althagafi.nebras@gmail.com
Purpose: To evaluate the perception of six esthetic components of the smile among dental students and whether such a perception was influenced by different education levels and gender. Materials and Methods: This was an analytical cross-sectional study. A self-administered questionnaire was applied to all students $(\mathrm{n}=182)$ at clinical levels (year four and five) to evaluate a total of 6 ideal images (smile arc [SA], buccal corridor [BC], gingival display [GD], midline diastema $[\mathrm{MD}]$, crown length $[\mathrm{CL}]$ and width [CW]). In addition, students were asked to evaluate 20 altered images of these ideal images. A 10-point visual analogue scale was used to assess the ideal images, with the right end of the scale labeled "attractive smile" and represented by the number 10 and the left end of the scale labeled "unattractive smile" and represented by the number 0 . The opposite scoring was applied for the altered esthetics smile images. Descriptive statistics was run to report sample characteristics, and the Mann-Whitney $U$-tests were performed to compare clinical levels and gender on aspects of esthetic smile.

Results: The response rate was $80 \%$ (77 females and 68 males). Students at level five scored statistically significantly $(\mathrm{p}<0.001)$ higher towered attractive esthetic smile in ideal SA, while students at level four scored statistically significantly ( $\mathrm{p}=0.016$ and 0.006 , respectively) higher towered attractive esthetic smile in ideal GD and CL. At altered smile esthetics images evaluation, fifth year dental students scored statistically significantly $(\mathrm{p}=0.030,0.026$ and 0.028 , respectively) higher towered unattractive esthetic smile in two altered images of SA and one of BC. In contrast, fourth year dental students scored statistically significantly ( $p=0.022,0.048$, 0.027 , respectively) higher towered unattractive esthetic smile in one altered image of GD, midline diastema and crown width. Males in year four were more likely to score higher than females for ideal images meanwhile females in year five scored higher than males towards attractive smile in ideal images. Males and females differences in scoring ideal images on both levels were generally non-significant $(\mathrm{P}>0.05)$ although males were statistically significantly to score higher than females towards unattractive images in both levels $(\mathrm{p}<0.05)$.

Conclusion: Dental students at the fifth-year level of study had higher perception of esthetic components of smile than those at the fourth-year level. At each level of study, female dental students apparently had higher perceptions of smile esthetics than males.

Keywords: dentistry, orthodontics, smile, beauty, dental students, perception, gender differences

\section{Introduction}

An increasing number of Saudi patients are seeking orthodontic treatment with a primary concern of esthetics. ${ }^{1}$ Modern dental care aims to enhance beauty, requiring an accurate and thorough analysis of the components that determine the attractiveness of a smile. Esthetics is one of the main reasons for patients seeking dental treatment, and a substantial part of the clinical practice of most dental 
practices is now influenced by esthetic dentistry. ${ }^{2}$ An attractive smile has long been the focal point of a person's commitment to enhancing their esthetic image and thereby self-esteem. In addition, the influence of the media on social expectations regarding people's appearance is likely to have played a role in recent advances in cosmetic dentistry. ${ }^{3}$

Smile analysis is an essential component of the overall facial analysis conducted by dental specialists. Evaluating the patient's smile helps the clinician to formulate an accurate treatment plan. ${ }^{4}$ To evaluate a smile, it is appropriate to determine those factors that play an important role in overall dental esthetics and smile aesthetics. Some of these factors include the extent of the incisors' and gingival exposure at rest and upon smiling, the smile arc, the dental midline relationship to the face midline, tooth proportions, and tooth shade. An esthetically attractive smile depends on the balance between these factors. ${ }^{5}$

The perception of smile esthetics is subjective and is influenced by geographical, racial, cultural, and demographic factors. ${ }^{3}$ The smile parameters for US and Canadian communities were evaluated by McLeod et al in 2011. ${ }^{6}$ These parameters included buccal corridor, gingival display, occlusal cant, discrepancy of maxillary midline to face, and gingival margin discrepancies. The researchers discovered clinically notable variations in all variables except the buccal corridor. However, the Canadians were more perceptive than the population of the United States. ${ }^{4}$ Significant variations have also been found between German, Russian, and Turkish people in the perception of smile esthetics. ${ }^{7}$

Several studies have been conducted to evaluate the perception of smile esthetics among both dental practitioners and the general public. The vast majority of these studies concluded that these groups vary considerably in their expectations for smile esthetics. ${ }^{89}$ Among the various dental specialties, orthodontists are more sensitive to dentofacial aesthetics than other dental professionals. ${ }^{4,10}$ In comparison, perceptions of aesthetics by dental students have a degree of variability due to the level of dental education they obtain on different aspects of dentistry. ${ }^{11}$ Dental students play a role as part of the dental workforce, and they should be able to recognize patients' needs and expectations, make clinical decisions in relation to dental aesthetics, and determine indications for treatment or referral. ${ }^{12}$ However, literature on the perception of smile aesthetics among dental students is still scarce.

Despite the many factors that may influence esthetic perception, including feelings, cultural background, and personal experiences, ${ }^{13}$ there seems to be an agreement in the literature that, regardless of these factors, dental students' perception of smile esthetics improves throughout their study. ${ }^{14}$ After the third year of dental school, students begin to focus on more detailed knowledge of dentistry and smile aesthetics (in the clinical module of the curriculum). In comparison to fourth-year students, fifthyear students have seen more patients and received more clinical training.

Most of the studies published on smile esthetics perceptions have focused mainly on assessing the attractiveness of the smile without determining the variables that affect the esthetics of the smile. To the best of our knowledge, no previous studies have compared the perception of smile esthetics among dental students in Medina. Thus, regional research on the appraisal of esthetic smiles is needed, particularly in conservative societies such as $\mathrm{Al}$ Madinah Al Munawwarah, where veil use predominates among women of all age groups. The aim of this study was to evaluate the perception of six smile esthetic components among dental students and whether such a perception was influenced by gender or clinical training.

\section{Materials and Methods}

\section{Study Design, Setting, and Sampling}

This was an exploratory analytical cross-sectional study conducted at college of Dentistry, Taibah University, AlMadinah AlMunawwarah, Saudi Arabia (SA) over the period between September 2017 and May 2018. The study has invited all the students $(\mathrm{n}=182)$ who attended 4 th and 5 th year levels. The students at these levels are expose to the knowledge and the clinical experience of smile esthetics training of orthodontics. Fourth year preclinical orthodontics is mainly conducted in the dental laboratory. Fifth year clinical orthodontics involving patient examination, development of a problem list. Students must be aware of the basic concepts of smile esthetics because addressing it involves a multidisciplinary approach rather than orthodontics alone.

\section{Data Collection Tool and Assessment of Smile Esthetics}

A self-administered paper and pencil questionnaire was distributed to all participating fourth- and fifth-year dental students in the classroom prior to their scheduled lectures. The questionnaires were anonymous, and participation was voluntary. The questionnaire contained a cover page that 
explained the study objectives; information about the ethical committee approving the study, for any inquiries and complaints; the email address of the researcher; and the time needed to fill out the form. There were two sections of the questionnaire: section one asks questions about socio-demographic characteristics (eg, gender and level of education). In section two, participants were asked to assess esthetic smiles using a 10-point visual analogue scale (VAS), of which the right end of the scale is labeled "attractive smile" and represented by the number 10, and the left end of the scale is labeled "unattractive smile" and represented by the number 0 . A coloured smile photograph was obtained of the female smile (The images were obtained from researcher's sister, who gave informed consent) using a digital camera (Nikon Coolpix 5000; Melville, New York, USA) in the frontal pose. A female individual was chosen who had a smile with characteristics close to standard norms as reported in the literature. ${ }^{15,16}$ Several photographs were taken so that natural smiles could be obtained. The pictures were taken under the same environmental and lighting conditions and standardized using Adobe Photoshop (Adobe Systems Inc., San Jose, CA, USA). A total of 26 digital images (Figures 1 and 2) were presented to the participants, each showing a frontal view of female smiles with similar skin tones. These images were selected to exhibit six different aspects or variables of smile esthetics. Each variable has one ideal image with other altered images of the same variable. All images were cropped to show the smile alone and remove the chin, nose, and cheeks to eliminate any conflicting variables that could influence the perception of a smile. ${ }^{17,18}$ These images were digitally edited using Adobe Photoshop software (Adobe Systems Inc., San Jose, CA, USA): the images were purposely adjusted to mimic a smile's esthetic variations. Then, the images were condensed or enlarged after the alterations were made to achieve an image size representing actual tooth size. The images were presented to the participants via Microsoft PowerPoint (Microsoft Corp., Microsoft Office 2016, NY, USA). The sequence of the images was randomized for each smile variable. The participants were given one minute to evaluate each image as reported previously. ${ }^{19}$ The images were divided into six sets (Figures 1 [Image 1-3] and 2 [Image 4-6]), each set based on a variable describing an aspect of smile esthetics. These variables include:

1. Smile Arc. The image was altered by flattening and accentuating the curvature of the anterior teeth
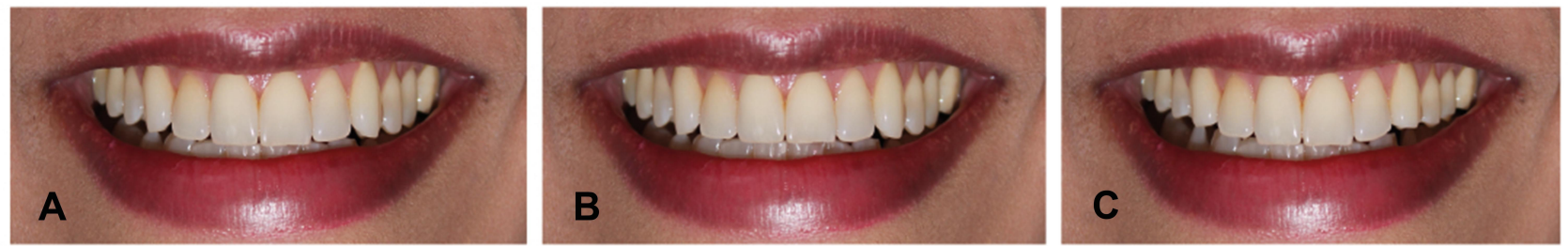

Image 1: (A) An ideal smile arc, (B) The smile arc is flat and (C) Excessive smile arc.
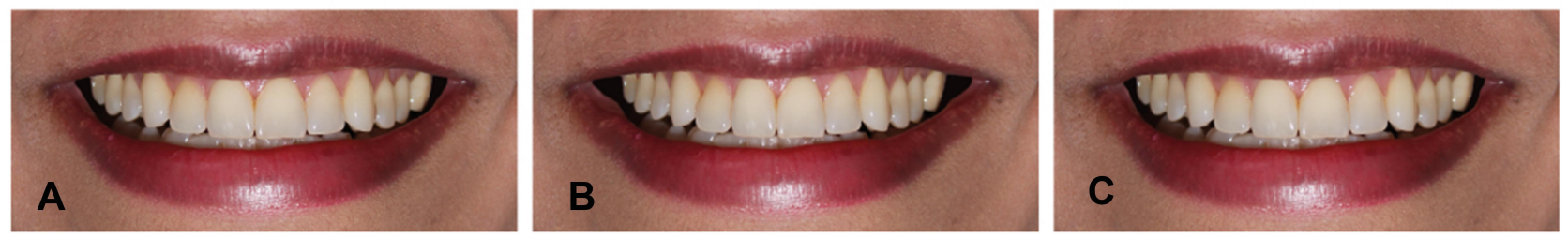

Image 2: (A) Control smile with ideal buccal corridors, (B) Narrow and (C) Wide buccal corridors.
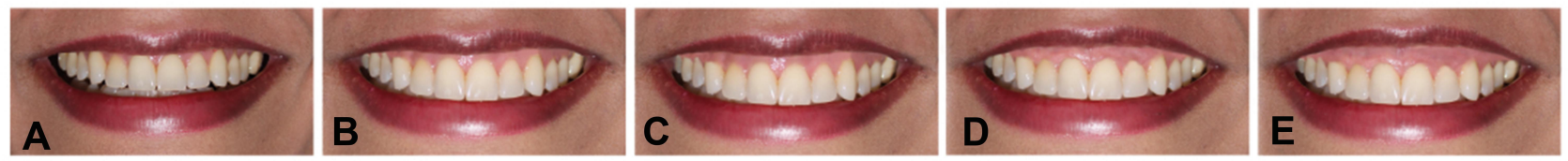

Image 3: (A) No alteration in gingival display (control), (B) Gingival display of $1 \mathrm{~mm},(C) 2 \mathrm{~mm}$, (D) $3 \mathrm{~mm}$ and (E) 4 $\mathrm{mm}$.

Figure I Aspect of smile esthetics for smile arc, buccal corridor, and gingival display. 
relative to the curvature of the lower lip (Figure 1, Image 1).

2. Buccal corridor. The image was altered by widening and narrowing the space between the posterior teeth buccal surfaces and the lip commissures (Figure 1, Image 2).

3. Gingival display upon smiling. The anterior gingival display was measured from the lower border of the upper lip till the gingival margin of the anterior teeth. The gingival show (gingiva-to-lip distance) was increased by $1 \mathrm{~mm}$ increments to create a "gummy" smile. Modifications were based on the relationship of the upper lip with the gingival margin of the maxillary incisors. The image was altered by increasing the amount of gingival show upon smiling, from $1 \mathrm{~mm}$ to $4 \mathrm{~mm}$ increase (Figure 1, Image 3).

4. Midline diastema. The image was altered by creating a midline diastema between the maxillary central incisors by $0.5 \mathrm{~mm}$ increments up to $2 \mathrm{~mm}$ (Figure 2, Image 1).

5. Crown length. The image was altered by decreasing the crown length of the maxillary left central incisor by adjusting the gingival marginal level by 0.5 increments up to $2 \mathrm{~mm}$. The reference point used for these measurements was the most superior point on the labial gingival margin of the adjacent right central incisor. An anterior tooth was selected so that we can reproduce the crown length alterations more easily (Figure 2, Image 2).

6. Crown width. Maxillary tooth width proportions provide an example of the golden proportion. The width of the lateral incisor should be around $62 \%$ of the width of the central incisor. ${ }^{10}$ The size of maxillary right lateral incisor was altered digitally to obtain an incremental decrease in lateral-to-central width proportion in contrast to the ideal smile that followed the golden-proportion (62\%). The most common variation in incisor crown width is usually associated with the size of the maxillary lateral incisors; hence, the alterations of crown width were made to the maxillary lateral incisor. The image was altered by decreasing the mesiodistal width of the maxillary right lateral incisor by an increment of $1 \mathrm{~mm}$ up to $4 \mathrm{~mm}$ crown width reduction (Figure 2, Image 3).

\section{Ethical Considerations}

This study was approved by the Dentistry Research Ethics Committee at Taibah University Dental College and Hospital (TUCDREC/20180127/Nazar). The study was conducted in accordance with the principles of the World
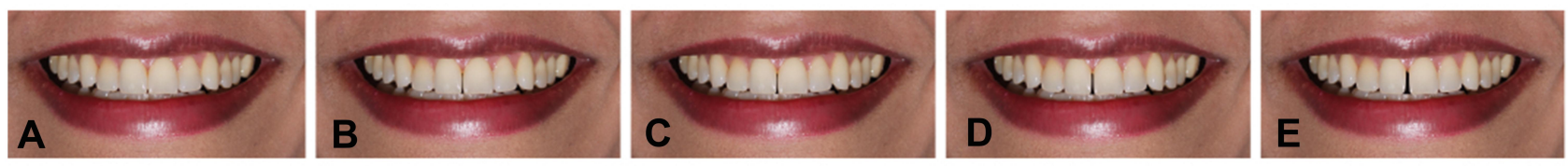

Image 4: (A) No alteration in midline diastema (control), (B) Midline diastema of $0.5 \mathrm{~mm}$, (C) $1 \mathrm{~mm}$, (D) $1.5 \mathrm{~mm}$ and (E) $2 \mathrm{~mm}$.
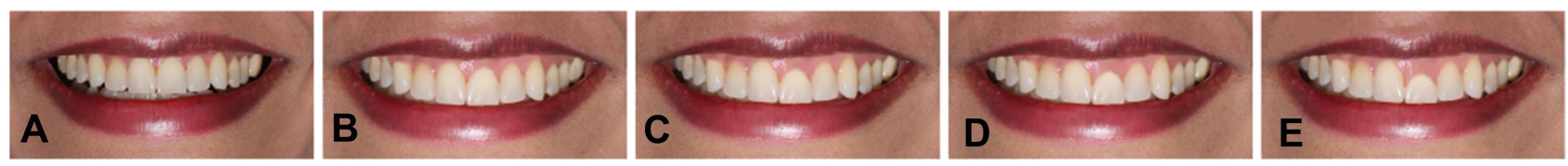

Image 5: Photographs showing changes to the crown length of the maxillary left central incisors. (A) Control, (B) 0.5 $\mathrm{mm},(C) 1.0 \mathrm{~mm}$, (D) $1.5 \mathrm{~mm}$ and $(E) 2.0 \mathrm{~mm}$, decrease in the length of the maxillary central incisors.
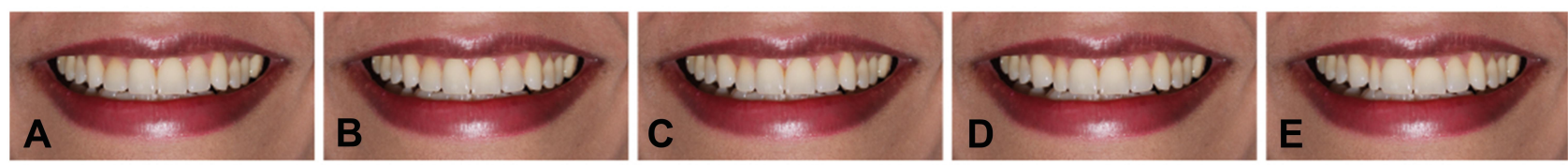

Image 6: Photographs displaying alterations to maxillary lateral incisors crown width. (A) Control, (B) $1 \mathrm{~mm}$, (C) 2 $\mathrm{mm}$, (D) $3 \mathrm{~mm}$ and (E) $4 \mathrm{~mm}$, decrease in the width of the maxillary lateral incisors.

Figure 2 Aspect of smile esthetics for midline diastema, length of the left crown maxillary central incisors and width of the lateral maxillary incisor crown. 
Medical Association, Declaration of Helsinki. Participation in the study was voluntary, and the confidentiality of the collected data were assured-ie, the questionnaire was anonymous and coded. The completion and return of the questionnaire were a proxy for consent to participate.

\section{Statistical Analysis}

The data were analyzed using the Statistical Package for the Social Sciences (SPSS) software, version 16.0 (SPSS, Inc., Chicago, IL, USA). Descriptive statistics that included median and interquartile range (IQR) for continuous variables and frequencies with percentages ( $\mathrm{F}[\%]$ ) for categorical data were run to report sample characteristics. Comparisons between dental students at fourth level, fifth level, male and female dental students collectively and at each level (fourth and fifth year) were undertaken. The comparisons were performed using the nonparametric analysis Mann-Whitney $U$-test as all the continuous data did not adhere to normality distribution (Kolmogorov-Smirnov $\leq 0.05$ ). Median (IQR) was reported for comparisons and when there were ties in medians, ie, medians were identical, the mean rank checked to aid interpretation of identical medians. The significance level was set at $0.05(\mathrm{P} \leq 0.05)$.

\section{Results}

Of all the invited students (182), the number of participating students as 145) (response rate $80 \%$ ), of whom 77 $(53.1 \%)$ were females and $68(46.9 \%)$ were males. Fiftyfour percent (35 female and 43 male) were in the fourth year and forty-six percent (42 female and 25 male) were in the fifth year.

Table 1 displays smile esthetics evaluation between male and female dental students at fourth and fifth year $(\mathrm{n}=145[$ Female $=77$, Male $=68])$. In evaluating ideal smile esthetic images (A), both male and female were scored comparably higher toward attractive esthetic for the smile arc, buccal corridor, gingival display, midline diastema, crown length and width and the difference between the two groups was non-significant $(\mathrm{p}=0.919,0.205,0.347$, $0.902,0.145$ and 0.062 , respectively). In addition, both groups were comparable on the altered images evaluation of smile arc, buccal corridor $(\mathrm{p}=0.778$ and 338)). On the other hand, there was a statistical significant difference between male and female dental students median scores

Table I. Comparison of Median Esthetic Scores of Different Smile Esthetics Variables as Evaluated by Male and Female Dental Students Collectively at Fourth and Fifth Year $(n=145[$ Female= 77, Male $=68])$

\begin{tabular}{|c|c|c|c|c|c|c|}
\hline \multirow{2}{*}{$\begin{array}{l}\text { Smile } \\
\text { Variables }\end{array}$} & \multirow[t]{2}{*}{ Gender } & \multicolumn{5}{|c|}{ Images' Median (IQR) Scores } \\
\hline & & $\mathbf{A}$ & B & C & D & $\mathbf{E}$ \\
\hline \multirow[t]{3}{*}{ Smile arc } & Female & $5(3)$ & $5(3)$ & $7(3)$ & - & - \\
\hline & Male & $5(4)$ & $5(3)$ & $6(3)$ & - & - \\
\hline & $P$-value & 0.919 & 0.778 & 0.383 & - & - \\
\hline \multirow[t]{3}{*}{ Buccal corridor } & Female & $6(2)$ & $7(3)$ & $7(3)$ & - & - \\
\hline & Male & $6(3)$ & $7(3)$ & $6.5(2)$ & - & - \\
\hline & p-value & 0.205 & 0.941 & 0.947 & - & - \\
\hline \multirow[t]{3}{*}{ Gingival display } & Female & $4(3)$ & $6(4)$ & $2(2)$ & $2(3)$ & $I(3)$ \\
\hline & Male & $4(3)$ & $5(2)$ & $3(3)$ & $3(4)$ & $3(3)$ \\
\hline & $P$-value & 0.347 & 0.048 & 0.094 & 0.087 & 0.005 \\
\hline \multirow[t]{3}{*}{ Midline diastema } & Female & $4(3)$ & $3(3)$ & $4(2)$ & $3(2)$ & $7(2)$ \\
\hline & Male & $4.5(3)$ & $4(2)$ & $4(2)$ & $4(3)$ & $6(2)$ \\
\hline & $P$-value & 0.902 & 0.012 & 0.243 & 0.008 & 0.054 \\
\hline \multirow[t]{3}{*}{ Crown length } & Female & $3(2)$ & I (2) & $4.50(3)$ & I (3) & $0(2)$ \\
\hline & Male & $3(2)$ & $2(3)$ & $5(3)$ & $2(2)$ & I (3) \\
\hline & $P$-value & 0.145 & 0.006 & 0.548 & 0.115 & 0.001 \\
\hline \multirow[t]{3}{*}{ Crown width } & Female & $5.5(3)$ & $3(3)$ & $4(3)$ & $2(2)$ & $5(3)$ \\
\hline & Male & $5(2)$ & $3(3)$ & $3.50(3)$ & $3(2)$ & $5(3)$ \\
\hline & P-value & 0.062 & 0.401 & 0.835 & 0.015 & 0.283 \\
\hline
\end{tabular}

Abbreviation: IQR, interquartile range. 
$(p<0.05)$ at the altered smile esthetics evaluation in all smile variables (B, D and $\mathrm{E}$ ). Male median scores were statistically significantly $(p<0.05)$ higher than females towards unattractive aesthetics in gingival display (E), midline diastema $(B, D)$, crown length $(B, E)$ and crown width (D) meanwhile females scores were higher at gingival display (B).

As for gender differences in academic level year four $(n=78[$ Female $=35$, Male=43]), Table 2 shows that the gender differences in scoring ideal esthetic smile for all variables were non-significant $(\mathrm{p}>0.05)$, except crown length where males scored statistically significantly higher towered ideal smile esthetics $(p=0.019)$. As for the evaluation of altered smile esthetics fourth year male dental students scored statistically significantly $(\mathrm{p}<0.05)$ higher than females toward the unattractive esthetic smile for gingival display (C, D and E), midline diastema (D) and crown length $(\mathrm{B}, \mathrm{C})$.

With regard to gender differences in academic level year five $(n=67[$ Female $=42$, Male $=25])$, Table 3 shows that ideal smile esthetics evaluation for all smile variables images (A), the gender differences were non-significant $(p>0.05)$. However, female dental students scored higher towered unattractive esthetic smile in altered smile images in the following smile variables: gingival display (B), midline diastema (E) and crown length $(\mathrm{C})$ and the difference was statistically significant $(p<0.05)$. On the other hand, male dental students scored higher towered unattractive esthetic smile in altered smile images compared to female counterparts in the following smile variables: midline diastema (B), crown length (E) and crown width (D) and the difference were statistically significant $(\mathrm{P}=0.006$, 0.005 and 0.014 , respectively).

Table 4 shows the differences in the academic level in evaluating smile esthetics $(n=145$ [fourth year=78, fifth year=67]). Students at level five scored statistically significantly $(\mathrm{p}<0.001)$ higher towered attractive esthetic smile in ideal smile arc image (A), while students at level four scored statistically significantly $(\mathrm{p}=0.016$ and 0.006 , respectively) higher towered attractive esthetic smile in ideal gingival display and crown length image (A). At altered smile esthetics evaluation, fifth year dental students scored statistically significantly $(\mathrm{p}=0.030,0.026$ and 0.028 respectively) higher towered unattractive esthetic smile in smile arc (B, C) and buccal corridor (C). On the other hand, fourth year dental students scored

Table 2. Comparison of Median Esthetic Scores of Different Smile Variables as Evaluated by Male and Female Dental Students at Fourth Year $(n=78$ [Female=35, Male=43])

\begin{tabular}{|c|c|c|c|c|c|c|}
\hline \multirow{2}{*}{$\begin{array}{l}\text { Smile } \\
\text { Variables }\end{array}$} & \multirow[t]{2}{*}{ Gender } & \multicolumn{5}{|c|}{ Images' Median (IQR) Scores } \\
\hline & & A & B & C & D & $\mathbf{E}$ \\
\hline \multirow[t]{3}{*}{ Smile arc } & Female & $4(2)$ & $5(2)$ & $6(2)$ & - & - \\
\hline & Male & $5(3)$ & $5(3)$ & $6(2)$ & - & - \\
\hline & $P$-value & 0.089 & 0.129 & 0.947 & - & - \\
\hline \multirow[t]{3}{*}{ Buccal corridor } & Female & $5(2)$ & $7(3)$ & $6(4)$ & - & - \\
\hline & Male & $6(2)$ & $7(3)$ & $6(2)$ & - & - \\
\hline & $P$-value & 0.158 & 0.632 & 0.537 & - & - \\
\hline \multirow[t]{3}{*}{ Gingival display } & Female & $4(4)$ & $6(4)$ & $2(2)$ & $2(3)$ & I (3) \\
\hline & Male & $6(2)$ & $6(2)$ & $4(3)$ & $4(3)$ & $3(3)$ \\
\hline & $P$-value & 0.053 & 0.677 & 0.009 & 0.004 & 0.005 \\
\hline \multirow[t]{3}{*}{ Midline diastema } & Female & $4(4)$ & $4(3)$ & $4(3)$ & $3(3)$ & $7(2)$ \\
\hline & Male & $5(3)$ & $4(2)$ & $4(1)$ & $4(2)$ & $7(2)$ \\
\hline & $P$-value & 0.964 & 0.544 & 0.727 & 0.013 & 0.890 \\
\hline \multirow[t]{3}{*}{ Crown length } & Female & $3(2)$ & I (2) & $4(3)$ & I (3) & I (2) \\
\hline & Male & $4(2)$ & $2(2)$ & $5(3)$ & $2(3)$ & $2(3)$ \\
\hline & $P$-value & 0.019 & 0.014 & 0.003 & 0.079 & 0.078 \\
\hline \multirow[t]{3}{*}{ Crown width } & Female & $6(3)$ & $3(4)$ & $3(4)$ & $3(4)$ & $5(3)$ \\
\hline & Male & $5(2)$ & $3(4)$ & $4(3)$ & $3(2)$ & $5(2)$ \\
\hline & $P$-value & 0.201 & 0.435 & 0.972 & 0.499 & 0.604 \\
\hline
\end{tabular}

Abbreviation: IQR, interquartile range. 
Table 3. Comparison of Median Esthetic Scores of Different Smile Variables as Evaluated by Male and Female Dental Students at Fifth Year $(n=67$ [Female=42, Male=25])

\begin{tabular}{|c|c|c|c|c|c|c|}
\hline \multirow{2}{*}{$\begin{array}{l}\text { Smile } \\
\text { Variables }\end{array}$} & \multirow[t]{2}{*}{ Gender } & \multicolumn{5}{|c|}{ Images' Median (IQR) Scores } \\
\hline & & $\mathbf{A}$ & B & C & D & $\mathbf{E}$ \\
\hline \multirow[t]{3}{*}{ Smile arc } & Female & $6(3)$ & $6(4)$ & $7(2)$ & - & - \\
\hline & Male & $5(4)$ & $5(2)$ & $7(4)$ & - & - \\
\hline & $P$-value & 0.494 & 0.503 & 0.599 & - & - \\
\hline \multirow[t]{3}{*}{ Buccal corridor } & Female & $7(4)$ & $7(4)$ & $7(2)$ & - & - \\
\hline & Male & $7(3)$ & $7(3)$ & $7(4)$ & - & - \\
\hline & $P$-value & 0.358 & 0.549 & 0.859 & - & - \\
\hline \multirow[t]{3}{*}{ Gingival display } & Female & $4(2)$ & $6(4)$ & $2(2)$ & $3(3)$ & $\mathrm{I}(2)$ \\
\hline & Male & $3(2)$ & $4(2)$ & $2(3)$ & $2(2)$ & $\mathrm{I}(3)$ \\
\hline & $P$-value & 0.140 & $<0.001$ & 0.289 & 0.372 & 0.478 \\
\hline \multirow[t]{3}{*}{ Midline diastema } & Female & $4(3)$ & $3(3)$ & $4(3)$ & $2(2)$ & $7(3)$ \\
\hline & Male & $4(1)$ & $4(2)$ & $4(2)$ & $3(2)$ & $5(3)$ \\
\hline & $P$-value & 0.937 & 0.006 & 0.354 & 0.447 & 0.002 \\
\hline \multirow[t]{3}{*}{ Crown length } & Female & $3(2)$ & I (2) & $5(3)$ & I (2) & $0.00(I)$ \\
\hline & Male & $3(2)$ & I (3) & $4(3)$ & $2(2)$ & I (2) \\
\hline & $P$-value & 0.272 & 0.213 & 0.010 & 0.873 & 0.005 \\
\hline \multirow[t]{3}{*}{ Crown width } & Female & $5(3)$ & $3(2)$ & $4(3)$ & $2(2)$ & $5(2)$ \\
\hline & Male & $4(2)$ & $3(2)$ & $3(2)$ & $3(2)$ & $4(2)$ \\
\hline & $P$-value & 0.060 & 0.138 & 0.513 & 0.014 & 0.069 \\
\hline
\end{tabular}

Abbreviation: IQR, interquartile range.

statistically significantly $(\mathrm{p}=0.022,0.048,0.027$ respectively) higher towered unattractive esthetic smile in gingival display (C), midline diastema (D) and crown width (D).

\section{Discussion}

Dental schools are responsible for ensuring the graduation of experienced clinicians who are independently qualified to practice dentistry. In current dental practice, esthetic dentistry is emerging rapidly. ${ }^{20}$ Dental students are usually required to treat patients during their undergraduate training. Therefore, in order to reach an accurate diagnosis and to plan the required treatment, it is crucial to teach dental students the principles of dentofacial esthetics. ${ }^{14,21,22}$

In the present study, six principal smile variables affecting the beauty of the smile - that is, smile arc, buccal corridor, gingival display, midline diastema, crown length, and crown width - were evaluated by dental students. ${ }^{23}$ Six sets of images were digitally manipulated, inducing minor modifications to investigate the effects of dental education, clinical training, and gender differences on the esthetic perception of smiles. A VAS was used to judge smile attractiveness. Various studies have adopted the use of the VAS as a study tool. ${ }^{1,4,12}$ To ensure consistency in presentation, PowerPoint presentations were performed in large classrooms that can accommodate up to 200 students.

This study involved investigating the influence of gender and education level on the perception of smile esthetics. This study found that there was no statistically significant difference $(\mathrm{p}>0.05)$ in esthetic perceptions toward attractive smiles and altered smiles images of smile arc, buccal corridor ( $>0.05$ ) between males and females. These results are comparable to those described in Bukhary's study. ${ }^{14,17,24}$ In the light of the literature, it is suggested that the gender effect in dentofacial esthetic perception is highly dependent on culture. Despite this, females were likely to score numerically higher and toward the attractive esthetic smile than males for gingival display and midline diastema. ${ }^{16}$ This is in agreement with the findings of Abu Alhaija et al, ${ }^{16}$ who reported that gender affects the smile attractiveness rating, and females were more sensitive to the presence of a gingival display and midline diastema than males. In contrary to the results of Moore et $\mathrm{al}^{25}$ and Ioi et $\mathrm{al}^{26}{ }^{26}$ who indicated that males and females rated smile attractiveness comparably. ${ }^{25,26}$ 
Table 4. Comparison of Median Esthetic Scores of Different Smile Variables as Evaluated Collectively by Fourth- and Fifth-Year Dental Students $(n=145$ [Fourth Year=78, Fifth Year=67])

\begin{tabular}{|c|c|c|c|c|c|c|}
\hline \multirow{2}{*}{$\begin{array}{l}\text { Smile } \\
\text { Variables }\end{array}$} & \multirow[t]{2}{*}{ Level } & \multicolumn{5}{|c|}{ Images' Median (IQR) Scores } \\
\hline & & $\mathbf{A}$ & B & C & D & $\mathbf{E}$ \\
\hline \multirow[t]{3}{*}{ Smile arc } & Fourth year & $4(2)$ & $5(2)$ & $6(2)$ & - & - \\
\hline & Fifth year & $6(3)$ & $5(4)$ & $7(3)$ & - & - \\
\hline & $P$-value & $<0.001$ & $0.030^{\mathrm{a}}$ & 0.026 & - & - \\
\hline \multirow[t]{3}{*}{ Buccal corridor } & Fourth year & $6(2)$ & $7(3)$ & $6(3)$ & - & - \\
\hline & Fifth year & $7(3)$ & $7(3)$ & $7(2)$ & - & - \\
\hline & $P$-value & 1.00 & 0.944 & 0.028 & - & - \\
\hline \multirow[t]{3}{*}{ Gingival display } & Fourth year & $5(3)$ & $6(3)$ & $3(3)$ & $3(4)$ & $2(2)$ \\
\hline & Fifth year & $4(2)$ & $5(2)$ & $2(3)$ & $2(3)$ & I (3) \\
\hline & $P$-value & 0.016 & 0.482 & 0.022 & 0.179 & 0.29 \\
\hline \multirow[t]{3}{*}{ Midline diastema } & Fourth year & $5(3)$ & $4(2)$ & $4(2)$ & $4(3)$ & $7(2)$ \\
\hline & Fifth year & $4(2)$ & $3(2)$ & $4(2)$ & $2.50(2)$ & $6(3)$ \\
\hline & $P$-value & 0.550 & 0.090 & 0.059 & 0.048 & 0.269 \\
\hline \multirow[t]{3}{*}{ Crown length } & Fourth year & $3(2)$ & $2(3)$ & $5(3)$ & $2(2)$ & I (2) \\
\hline & Fifth year & $3(2)$ & I (3) & $5(4)$ & I (2) & $0.0(2)$ \\
\hline & $P$-value & $0.006^{b}$ & 0.185 & 0.339 & 0.328 & 0.100 \\
\hline \multirow[t]{3}{*}{ Crown width } & Fourth year & $5(2)$ & $3(3)$ & $3.50(3)$ & $3(3)$ & $5(3)$ \\
\hline & Fifth year & $5(2)$ & $3(2)$ & $3(4)$ & $2(2)$ & $4.50(2)$ \\
\hline & $P$-value & 0.111 & $0.012^{c}$ & 0.882 & 0.027 & 0.124 \\
\hline
\end{tabular}

Notes: ${ }^{\mathrm{a}} 5$ th year mean rank higher than 4 th year; ${ }^{\mathrm{b}} 4$ th year mean rank higher than 5 th year; ${ }^{\mathrm{c}} 4$ th year mean rank higher than 5 th year. Abbreviation: IQR, interquartile range.

The maxillary left central incisor's crown length was altered in our study. Crown length alterations were made by adjusting the gingival marginal level by 0.5 increments up to $2 \mathrm{~mm}$. Changing the proportions of the tooth reduces the perception of an esthetic smile. ${ }^{7,12,14,27}$ Moreover, any decrease in the tooth length or width is considered to decrease the smile's attractiveness when rated by either dentists or laypersons. ${ }^{24,28}$ Asymmetric gingival marginal level was perceived as unattractive by female dental students. They scored statistically significantly toward an unattractive esthetic smile in respect of crown length $(\mathrm{p}>0.05)$. This finding is similar to that reported by Alhammadi et $\mathrm{al}^{22}$ However, ideal smile esthetics evaluation for crown length images showed that gender differences were non-significant $(\mathrm{p}>0.05)$. In agreement with previous studies, no significant gender difference was found with respect to the gingival marginal level and crown length. ${ }^{12,14,17,24}$

In addition, the maxillary right lateral incisor's clinical crown width was modified. In our study, ideal smile esthetics evaluation for crown width images showed that gender differences were non-significant $(p>0.05)$.
However, the perception of correct lateral incisor crown width is higher among female dental students.

As for the academic level differences in evaluating smile esthetics, students at level five scored statistically significantly $(\mathrm{p}<0.05)$ higher towered attractive esthetic smile in ideal smile arc image and at altered smile esthetics evaluation in gingival display, midline diastema, and crown width. ${ }^{12,22}$ However, the findings support previous research that shows a link between dental knowledge (expressed as an academic level in this study) and esthetic perception of dentofacial features. Armalaite et $\mathrm{al}^{18}$ assessed how the characteristics of smiles are perceived by dental students. They reported that among dental students, fifth year dental students were more critical when evaluating smile esthetics. Alhammadi et $\mathrm{al}^{22}$ reported that clinical training has a significant positive effect on smile esthetic evaluation. This is, however, contrary to the findings of a study by Sakellaropoulos et $\mathrm{al}^{29}$ which indicated that education level was not an important factor.

Our study has a few limitations. The use of a female smile as the only model image is one of the study's limitations, as it has been shown that the gender of the 
model smile image influences smile attractiveness rating. ${ }^{16}$ Hence, the results may not be generalizable. ${ }^{4,16}$ Another limitation was the simultaneous presentation of images to all students in classrooms. The location of the students in the classroom may have influenced their responses and students may not have had the same view of the screen. This could have been combined with the students' vision acuity and normal color discrimination ability. The presence of disease/illnesses/disorders was not an exclusion criterion for participation in the study. ${ }^{29}$ Finally, our study did not take into account the socio-economic status of dental students, which may have affected the outcomes. As for recommendations, studying how specific curricular material affects students' dentofacial esthetic experience would appear to be a promising path for future studies. Dental students should be encouraged to discuss variations in the understanding of smile aesthetics while addressing patients' treatment plans. Moreover, dentofacial esthetic evaluation should include both male and female smile images to explore the evaluators' differences in terms of same gender smile image (Male-Male; Female to female, Male-Female and Female-Male) assessment. As for the clinical relevance, this study highlighted that more efforts should be done on both the dedicated and training of students of assessing esthetic smile. Specific focus should be paid to senior students who will be soon independent dentist serving the community. This is crucially important in order to be able to fulfill the patient's esthetic needs and expectations.

\section{Conclusion}

The findings of this study showed that dental students at the fifth year level (clinical level) generally had higher perception of aesthetic components of the smile than those at the fourth year level. Regardless of the level of study, female dental students had higher perceptions of esthetic components of the smile than males.

\section{Acknowledgments}

I would like to thank associate professor Dr. Shadia Abdelhameed Elsayed, College of Dentistry, Taibah University, Almadinah Almunawwarah, Saudi Arabia, for the guidance and critical comments on the manuscript. I extend my thanks as well to the participating students.

\section{Disclosure}

The author declares no conflicts of interest in this work.

\section{References}

1. Alhummayani FM, Taibah SM. Orthodontic treatment needs in Saudi young adults and manpower requirements. Saudi Med J. 2018;39 (8):822-828. doi:10.15537/smj.2018.8.22337

2. Aldeeri AA, Alhababi KA, Algahtani FA, Tounsi AA, Albadr KI. Perception of altered smile esthetics by orthodontists, dentists, and laypeople in Riyadh, Saudi Arabia. Clin Cosmet Investig Dent. 2020;12:563-570. doi:10.2147/CCIDE.S272226

3. Saha MK, Khatri M, Saha SG, et al. Perception of acceptable range of smiles by specialists, general dentists and lay persons and evaluation of different aesthetic paradigms. J Clin Diagn Res. 2017;11(2): ZC25-ZC28. doi:10.7860/JCDR/2017/23359.9274

4. Al Taki A, Khalesi M, Shagmani M, et al. Perceptions of altered smile esthetics: a comparative evaluation in orthodontists, dentists, and laypersons. Int J Dent. 2016;2016(2):7815274. doi:10.1155/ 2016/7815274

5. Oreški NP, Čelebić A, Petričević N. Assessment of esthetic characteristics of the teeth and surrounding anatomical structures. Acta Stomatol Croat. 2017;51(1):22-32. doi:10.15644/asc51/1/3

6. McLeod C, Fields HW, Hechter F, Wiltshire W, Rody WJ, Christensen J. Esthetics and smile characteristics evaluated by laypersons. Angle Orthod. 2011;81(2):198-205. doi:10.2319/060510309.1

7. Talic N, Alomar S, Almaidhan A. Perception of Saudi dentists and lay people to altered smile esthetics. Saudi Dent J. 2013;25(1):13-21. doi:10.1016/j.sdentj.2012.09.001

8. Pogrel MA. What are normal esthetic values? J Oral Maxillofac Surg. 1991;49(9):963-969. doi:10.1016/0278-2391(91)90060-y

9. Prahl-Andersen B, Boersma H, van der Linden FP, Moore AW. Perceptions of dentofacial morphology by laypersons, general dentists, and orthodontists. J Am Dent Assoc. 1979;98(2):209-212. doi:10.14219/jada.archive. 1979.0456

10. Kokich VO, Kokich VG, Kiyak HA. Perceptions of dental professionals and laypersons to altered dental esthetics: asymmetric and symmetric situations. Am J Orthod Dentofac Orthop. 2006;130 (2):141-151. doi:10.1016/j.ajodo.2006.04.017

11. Dar-Odeh N, Elsayed SA, Nourwali I, Ryalat S, Al-Shayyab MH, Abu-Hammad O. Social factors as career obstacles for female oral and maxillofacial surgeons in three Middle Eastern countries. Int $J$ Oral Maxillofac Surg. 2019;48(11):1504-1508. doi:10.1016/j.ijom.20 19.03.001

12. Aldhorae K, Alqadasi B, Altawili ZM, Assiry A, Shamalah A, AlHaidari SA. Perception of dental students and laypersons to altered dentofacial aesthetics. J Int Soc Prev Community Dent. 2020;10 (1):85-95. doi:10.4103/jispcd.JISPCD_340_19

13. Zadra JR, Clore GL. Emotion and perception: the role of affective information. Wiley Interdiscip Rev Cogn Sci. 2011;2(6):676-685. doi: $10.1002 /$ wcs. 147

14. Romsics L, Segatto A, Boa K, et al. Dentofacial mini- and microesthetics as perceived by dental students: a cross-sectional multi-site study. PLoS One. 2020;15(3):e0230182. doi:10.1371/journal.pone.02 30182

15. Rufenacht CR. Fundamentals of Esthetics. 2nd ed. Chicago: Quintessence Pub.Co; 1990.

16. Abu Alhaija ESJ, Al-Shamsi NO, Al-Khateeb S. Perceptions of Jordanian laypersons and dental professionals to altered smile aesthetics. Eur J Orthod. 2011;33(4):450-456. doi:10.1093/ejo/ cjq100

17. Omar H, Tai Y. Perception of smile esthetics among dental and nondental students. J Educ Ethics Dent. 2014;4(2):54. doi:10.4103/ 0974-7761.148986

18. Armalaite J, Jarutiene M, Vasiliauskas A, et al. Smile aesthetics as perceived by dental students: a cross-sectional study. BMC Oral Health. 2018;18(1):225. doi:10.1186/s12903-018-0673-5 
19. Sriphadungporn C, Chamnannidiadha N. Perception of smile esthetics by laypeople of different ages. Prog Orthod. 2017;18(1):8. doi:10.1186/s40510-017-0162-4

20. Cotrim ER, Vasconcelos Júnior ÁV, Haddad AC, Reis SA. Perception of adults' smile esthetics among orthodontists, clinicians and laypeople. Dental Press J Orthod. 2015;20(1):40-44. doi:10.1590/ 2176-9451.20.1.040-044.oar

21. Miller CJ. The smile line as a guide to anterior esthetics. Dent Clin North Am. 1989;33(2):157-164.

22. Alhammadi MS, Halboub E, Al-Mashraqi AA, et al. Perception of facial, dental, and smile esthetics by dental students. J Esthet Restor Dent. 2018;30(5):415-426. doi:10.1111/jerd.12405

23. Menezes EBC, Bittencourt MAV, Machado AW. Do different vertical positions of maxillary central incisors influence smile esthetics perception? Dental Press J Orthod. 2017;22(2):95-105. doi:10.1590/ 2177-6709.22.2.095-105.oar

24. Bukhary SMN, Gill DS, Tredwin CJ, Moles DR. The influence of varying maxillary lateral incisor dimensions on perceived smile aesthetics. Br Dent J. 2007;203(12):687-693. doi:10.1038/bdj.2007. 1110
25. Moore T, Southard KA, Casko JS, Qian F, Southard TE. Buccal corridors and smile esthetics. Am J Orthod Dentofac Orthop. 2005;127(2):208-213. doi:10.1016/j.ajodo.2003.11.027

26. Ioi H, Nakata S, Counts AL. Effects of buccal corridors on smile esthetics in Japanese. Angle Orthod. 2009;79(4):628-633. doi:10. 2319/080708-410.1

27. Kim SK, Kim OS. Analysis of esthetic factors and evaluation of esthetic perception for maxillary anteriors of dental students. $J$ Korean Acad Prosthodont. 2019;57(2):118-126. doi:10.4047/ jkap.2019.57.2.118

28. Daou R, Akl R, Ghoubril J, Khoury E. Influence of the vertical position of maxillary lateral incisors on the perception of smile esthetics among dentists, orthodontists and laypersons: a computerized simulated photographic assessment. Int Arab J Dent. $2019 ; 10$.

29. Sakellaropoulos O, Lagouvardos P. Influence of lightness of teeth and lip position of a posed smile on the perception of its attractiveness. Int J Esthet Dent. 2020;15(2):158-172.

\section{Publish your work in this journal}

Clinical, Cosmetic and Investigational Dentistry is an international, peer-reviewed, open access, online journal focusing on the latest clinical and experimental research in dentistry with specific emphasis on cosmetic interventions. Innovative developments in dental materials, techniques and devices that improve outcomes and patient satisfaction and preference will be highlighted. The manuscript management system is completely online and includes a very quick and fair peer-review system, which is all easy to use. Visit http://www.dovepress.com/testimonials.php to read real quotes from published authors. 